\title{
Tribological Performance of Diamond-like Nanocomposite Coatings: Influence of Environments and Laser Surface Texturing
}

\author{
Sergei M. Pimenov ${ }^{1, * \mathbb{D}}$, Evgeny V. Zavedeev ${ }^{1}$, Olga S. Zilova ${ }^{2}$, Alexander P. Lepekhov ${ }^{2}$, Beat Jaeggi ${ }^{3,+}$ \\ and Beat Neuenschwander ${ }^{3}$ (D) \\ 1 Prokhorov General Physics Institute of the Russian Academy of Sciences, 119991 Moscow, Russia; \\ zavedeev@nsc.gpi.ru \\ 2 National Research University “Moscow Power Engineering Institute”, 111250 Moscow, Russia; \\ zososz@yandex.ru (O.S.Z.); a.p.lepekhov@mail.ru (A.P.L.) \\ 3 Institute for Applied Laser, Photonics and Surface Technologies ALPS, Bern University of Applied Sciences, \\ CH-3400 Burgdorf, Switzerland; BJaeggi@lasea.com (B.J.); beat.neuenschwander@bfh.ch (B.N.) \\ * Correspondence: pimenov@nsc.gpi.ru \\ † Present address: Lasea Switzerland SA, CH-2502 Biel/Bienne, Switzerland.
}

\section{check for}

updates

Citation: Pimenov, S.M.; Zavedeev, E.V.; Zilova, O.S.; Lepekhov, A.P.;

Jaeggi, B.; Neuenschwander, B.

Tribological Performance of

Diamond-like Nanocomposite

Coatings: Influence of Environments and Laser Surface Texturing. Coatings 2021, 11, 1203. https://doi.org/ $10.3390 /$ coatings 11101203

Academic Editor: Diego

Martínez Martínez

Received: 30 August 2021

Accepted: 28 September 2021

Published: 30 September 2021

Publisher's Note: MDPI stays neutral with regard to jurisdictional claims in published maps and institutional affiliations.

Copyright: (c) 2021 by the authors. Licensee MDPI, Basel, Switzerland. This article is an open access article distributed under the terms and conditions of the Creative Commons Attribution (CC BY) license (https:// creativecommons.org/licenses/by/ $4.0 /)$.

\begin{abstract}
Diamond-like nanocomposite (DLN) films (a-C:H:Si:O films) are characterized by their unique structure and remarkable tribological properties to be pronounced under various environmental and surface modification conditions. In this paper, we investigated the effects of environments (humid air, water and oil lubrication, elevated temperatures) and laser surface texturing on tribological performance of DLN coatings. Femtosecond laser (wavelength $515 \mathrm{~nm}$ ) was used for surface texturing. Comparative tests of DLN films sliding against different counterbodies (steel, $\mathrm{Si}_{3} \mathrm{~N}_{4}$ ) in humid air and water demonstrated the low-friction and low-wear performance under water, in the absence of chemical interaction of water with the counterbody surface. The wear rates of the film and $\mathrm{Si}_{3} \mathrm{~N}_{4}$ ball in water, $7.5 \times 10^{-9}$ and $2.6 \times 10^{-9} \mathrm{~mm}^{3} /(\mathrm{Nm})$, were found to be considerably lower than the corresponding values $6.8 \times 10^{-7}$ and $3.8 \times 10^{-8} \mathrm{~mm}^{3} /(\mathrm{Nm})$ in humid air, in spite of higher friction in water-lubricated sliding. Laser surface texturing of DLN films was performed to fabricate microcrater arrays, followed by tribological testing under oil lubrication at different temperatures, from 23 to $100{ }^{\circ} \mathrm{C}$. The lubricated friction performance of laser-textured films was improved at both the room temperature and elevated temperatures. The friction coefficient was reduced from 0.1 (original film) to 0.083 for laser-textured film at room temperature, and then to 0.068 at $100{ }^{\circ} \mathrm{C}$. The nano-/microfriction behavior of laser-structured surface characterized by lower friction forces than the original surface was demonstrated using friction force microscopy in ambient air. The obtained results demonstrate excellent tribological properties of DLN coatings in various environments, which can be further improved by femtosecond-laser-surface texturing.
\end{abstract}

Keywords: diamond-like nanocomposite (DLN) films; tribology; humid environments; laser surface texturing; oil lubrication; friction force microscopy

\section{Introduction}

Diamond-like nanocomposite (DLN) a-C:H:Si:O films-a class of $\mathrm{SiO}_{x}$-containing hydrogenated diamond-like carbon (DLC) films - are characterized by the unique structure responsible for low internal stresses, high hardness and elastic modulus, enhanced adhesion to different substrates, and high thermal stability exceeding the thermal stability of hydrogenated a-C:H films [1-7]. The DLN films exhibit low-friction and low-wear properties under various sliding conditions [8-18], making them unrivalled protective and tribological coatings for many applications. The low-friction performance of DLN films in ambient air has been attributed to interfacial sliding between the DLN film and graphitized 
tribofilm formed on the ball counterface [11,12], confirmed also by later tribological studies of DLN films [15-17]. Of great interest is the friction and wear properties of DLN films under the conditions changing the graphitized tribofilm formation, e.g., under liquid (water, oil) lubrication, at elevated temperatures, which would extend the functional capabilities of the coatings.

Owing to low internal stresses [7], it is possible to produce DLN films of relatively large thickness (up to $10 \mu \mathrm{m}$ ), retaining the hardness and elastic properties $[7,19,20]$, which allows a laser surface texturing (LST) technique to be applied for further improvements of friction and wear properties of DLN coatings [16,20]. It was the small thickness (of $\sim 1 \mu \mathrm{m}$ ) that strongly limited the laser surface texturing of DLC films in early experiments of lubricated sliding, when the DLC film deposition onto laser-textured steel or silicon substrates had been proposed as an alternative texturing technique for DLC-coated surfaces [21-24]. This technique, alternative to direct laser surface texturing of DLC films, had disadvantages dealing with the need of mechanical polishing of laser-textured substrates before deposition of thin DLC films (to remove protruding rims around dimples) [21,23], and weaker adhesion of DLC coatings at the dimple edges leading to the film delamination during sliding [22]. Recently, femtosecond (fs) laser processing of DLN films has been demonstrated as an effective technique to control the friction properties at the nano, micro, and macroscale $[16,20,25-27]$ and to improve tribological properties of laser-textured DLN films in lubricated sliding $[16,26]$. Most of the important findings for fs-laser-textured DLN films are related to regular patterns of parallel microgrooves and arrays of microcraters fabricated under certain irradiation conditions limited to a given structure size of $\approx 10 \mu \mathrm{m}$ (groove width, crater diameter), structure depth of a few microns and period of $20 \mu \mathrm{m}$. Further optimization of laser surface texturing of DLN films is needed, aiming at fabrication of microstructures of lower size and higher aspect ratio, and increase in the throughput of microprocessing with high spatial precision.

In this paper we focus on the effects of environments and laser surface texturing on tribological performance of DLN coatings. Firstly, we present the results of comparative tribological testing of DLN films in humid air and water under linear reciprocating sliding against steel and silicon-nitride balls, and demonstrate the friction pair-dependent wear character of the rubbing materials under water lubrication. Secondly, we present experimental data of high-precision surface texturing of DLN films with fs-laser pulses and fabrication of microcrater-based structures of hexagonal geometry, followed by tribological testing of the laser-textured DLN samples under oil lubrication at room temperature and $100{ }^{\circ} \mathrm{C}$. In addition, we demonstrate how the nano-/microfriction behavior is changed in the laser-structured area consisting of microcraters using friction force microscopy in humid air.

\section{Materials and Methods}

\subsection{DLN Film Properties}

DLN films were grown on silicon and steel substrates using a plasma-assisted chemical vapor deposition (PACVD) from polymethylphenylsiloxane (PMPS) vapors [1,7]; PMPS is an organic-silicon liquid and its molecular formula is $\left(\mathrm{CH}_{3}\right)_{3} \mathrm{SiO}\left(\mathrm{CH}_{3} \mathrm{C}_{6} \mathrm{H}_{5} \mathrm{SiO}\right)_{3} \mathrm{Si}\left(\mathrm{CH}_{3}\right)_{3}$. The main parameters of the CVD system were described in our recent paper [7]. Briefly, the PACVD setup had two different sources (plasmatron and magnetron) for precursor supply into a vacuum chamber that allowed us to deposit either undoped DLN or metal-doped DLN films onto different substrates. The high-frequency potential $(1.76 \mathrm{MHz}, 0.1-1.5 \mathrm{kV})$ applied to the substrate holder provided the appearance of a negative constant bias voltage on the substrate; the bias voltage was in the range of -200 to $-700 \mathrm{~V}$. During DLN film growth, the PMPS vapor pressure did not exceed the value of $2.6 \times 10^{-2} \mathrm{~Pa}$. The film growth rate was 1-2 $\mu \mathrm{m} / \mathrm{h}$. The $\mathrm{Si}$ (100) plates of $20 \mathrm{~mm} \times 20 \mathrm{~mm} \times 0.52 \mathrm{~mm}$ size (cut from 4-inch Si wafers) and polished stainless steel (type 1.4301) plates of $24 \mathrm{~mm} \times 24 \mathrm{~mm}$ $\times 2 \mathrm{~mm}$ size were used as the substrates. In tribotests at elevated temperatures the DLN film-on-steel samples were used. 
The thickness ( $h$ ) of the DLN films was in the range from 2.4 to $5.2 \mu \mathrm{m}$. The chemical composition of the films was determined by the energy-dispersive X-ray spectroscopy analysis: the concentration of elements (excluding hydrogen) was in the range of $[C]=70-78$ at. $\%$, $[\mathrm{O}]=9-14$ at. $\%$ and $[\mathrm{Si}]=12-17$ at.\% The content of hydrogen in the films was $0.1-0.4$ of the atomic concentration of carbon, with the typical composition around $\left(\mathrm{CH}_{0.15}\right)_{0.7}\left(\mathrm{SiO}_{0.4}\right)_{0.3}[1,12]$. The hardness $(H)$ and elastic modulus $(E)$ of the DLN films were measured by nanoindentation using the nanoindenter NHT2-TTX, CSM Instruments SA at the load of 1-5 mN of a Berkovich diamond indenter. The $H$ and $E$ values were in the range of $H=15-28 \mathrm{GPa}$ and $E=96-182 \mathrm{GPa}$, mainly dependent on the bias voltage and rate of PMPS vapors supply into the vacuum chamber. The internal (compressive) stresses in the films were in the range of 150-300 MPa. More details about the hardness, elastic properties, internal stresses, and adhesion evaluation of DLN films are given in ref. [7].

\subsection{Tribological Testing}

Tribological tests of DLN films in humid air $(\mathrm{RH}=50 \%)$ and in distilled water were performed using a ball-on-flat tribometer TRB-S-CE-0000, CSM Instruments SA under linear reciprocating sliding against $100 \mathrm{Cr} 6$ steel and $\mathrm{Si}_{3} \mathrm{~N}_{4}$ balls of $6-\mathrm{mm}$ diameter. The $\mathrm{RH}$ was determined using a psychrometric hygrometer. The test conditions were as follows: (i) the stroke length $8 \mathrm{~mm}$, (ii) the normal load $0.5 \mathrm{~N}$, (iii) the sliding speed $5 \mathrm{~cm} / \mathrm{s}$, (iv) the number of cycles $2 \times 10^{4}$, and (v) ambient temperature $20-25^{\circ} \mathrm{C}$. During the tests, the water was evaporated, and therefore, periodic addition of water to the contact zone was made. The above sliding parameters were selected similar to those used in our previous studies of DLN films $[16,19,20]$.

Tribological tests of the laser-textured sample under oil lubrication at two temperatures $\left(23\right.$ and $\left.100{ }^{\circ} \mathrm{C}\right)$ were carried out using a high-temperature ball-on-disc tribometer THT-S-AE-0000 (Anton Paar TriTec., Corcelles, Switzerland) against $\mathrm{Si}_{3} \mathrm{~N}_{4}$ balls of 6-mm diameter. The normal load was $1 \mathrm{~N}$, and the sliding speed was $5 \mathrm{~cm} / \mathrm{s}$. Other conditions of lubricated sliding are specified below in Section 3.2. In lubricated sliding tests, the MS-20 mineral oil without additives [28] was used. The MS-20 oil is characterized by high viscosity, high oxidative and thermal stability. The kinematic viscosity $(v)$ of the MS-20 oil is $v=945 \mathrm{~mm}^{2} / \mathrm{s}$ at $23^{\circ} \mathrm{C}, v=268 \mathrm{~mm}^{2} / \mathrm{s}$ at $40^{\circ} \mathrm{C}$ and $v=20.4 \mathrm{~mm}^{2} / \mathrm{s}$ at $100{ }^{\circ} \mathrm{C}$ [29]. In preparation to lubricated sliding, DLN film samples with laser-textured areas were completely covered by the oil lubricant and kept for at least $24 \mathrm{~h}$. Then the samples were centrifuged at $3000 \mathrm{rpm}$ for $2 \mathrm{~min}$ to obtain a uniform lubricant film on the surface. After the lubricated sliding tests, the DLN samples were rinsed with n-heptane to remove the oil films. The wear tracks on the film surface and wear scars on the ball surface were examined with optical microscopy (OM), stylus profilometry, and white light interferometry (WLI) (Zygo New View 5000, Middlefield, CT, USA) to determine the wear rates of the materials.

The surface relief and friction properties of laser-textured DLN films at the nano and microscale were studied with an atomic force microscope of the NTEGRA Spectra system (NT-MDT, Moscow, Russia) using a lateral force mode (LFM). AFM Si probes with the spring constant of $1-1.5 \mathrm{~N} / \mathrm{m}$ and tip radius of $R_{\text {tip }} \sim 0.5-1 \mu \mathrm{m}$ were used. The LFM measurements were carried out in ambient air at relative humidity $\mathrm{RH}=30-50 \%$ (measured with a humidity sensor installed in the system) and room temperature $T=25^{\circ} \mathrm{C}$.

\subsection{Femtosecond-Laser Surface Microstructuring (Texturing) of DLN Coatings}

Laser processing of DLN film samples was carried out using a SATSUMA HP2 femtosecond laser system [30,31] (from Amplitude Systèmes, Pessac, France) generating pulses of $\tau=320 \mathrm{fs}$ duration at the wavelength $\lambda=515 \mathrm{~nm}$. The average power $(P)$ was varied from 25 to $125 \mathrm{~mW}$ at the pulse repetition rate $f=100$ or $500 \mathrm{kHz}$; the pulse energy $(\varepsilon)$ was changed from 0.1 to $0.25 \mu \mathrm{J}$. In a number of laser surface structuring experiments, the 2-pulse-burst mode of irradiation was used due to higher ablation rates compared to the single-pulse irradiation regime [26]. A scheme of the burst generation with an ultra-short pulsed laser system was reported in [32]. The laser beam was focused with a 
100-mm telecentric objective, and the beam radius measured with a scanning slit beam profiler from Thorlabs amounted to $w_{0}=7.1 \mu \mathrm{m}$. A high precision galvanometer scanner intelliSCAN se from Scanlab (Puchheim, Germany) was used to control the scanning beam velocities $\left(V_{s}\right)$ and the spacing between spots $\left(V_{s} / f\right)$ in the range of 10 to $40 \mu \mathrm{m}$, providing the fabrication of regular microcrater arrays of different periods. In this work we consider the fs-laser-produced surface structures consisting of microcraters, while the fabrication and properties (tribological, wettability) of linear microstructures consisting of parallel microgrooves were reported elsewhere [16,20,27].

For regular microcrater arrays, the scanning beam velocity and the number of pulses $(N)$ per spot were the two main parameters to produce the patterns with the required period $(\Lambda)$ and depth $(d)$ of microcraters. Two irradiation regimes, differed primarily by the beam scanning conditions and pulse repetition rates, were used to produce the surface structures from microcraters. The first series of experiments was performed at $f=100 \mathrm{kHz}$ and corresponding scanning speed to obtain the spacing of $\Lambda=20 \mu \mathrm{m}$ between neighboring spots. During scanning along the $X$ direction, the laser beam was stopped at a given distance ranged from $\Lambda$ to $n \Lambda$ ( $n$ is the number of craters along the $X$ axis), and each spot was irradiated by $N$ pulses to produce a crater of a predefined depth. After structuring of a line of 5-10 mm length along the $X$ axis, the beam was returned to $X=0$, shifted along the $\mathrm{Y}$ axis by a distance equal to $\Lambda$ to continue the structuring along the next line and to repeat the procedure $m$ times ( $m$ is the number of lines along the $Y$ axis). This resulted in fabrication of laser-patterned surface areas of the $(n \Lambda) \times(m \Lambda)$ size and "square" geometry (i.e., with location of craters in the corners of squares of $\Lambda \times \Lambda$ size). AFM image and surface profile of such a microcrater array are shown in Figure $1 \mathrm{a}, \mathrm{b}$. It should be noted that the above structuring regime provided high precision but proved to be time-consuming due to specifics of the beam scanning for irradiation of each spot by $N$ laser pulses.
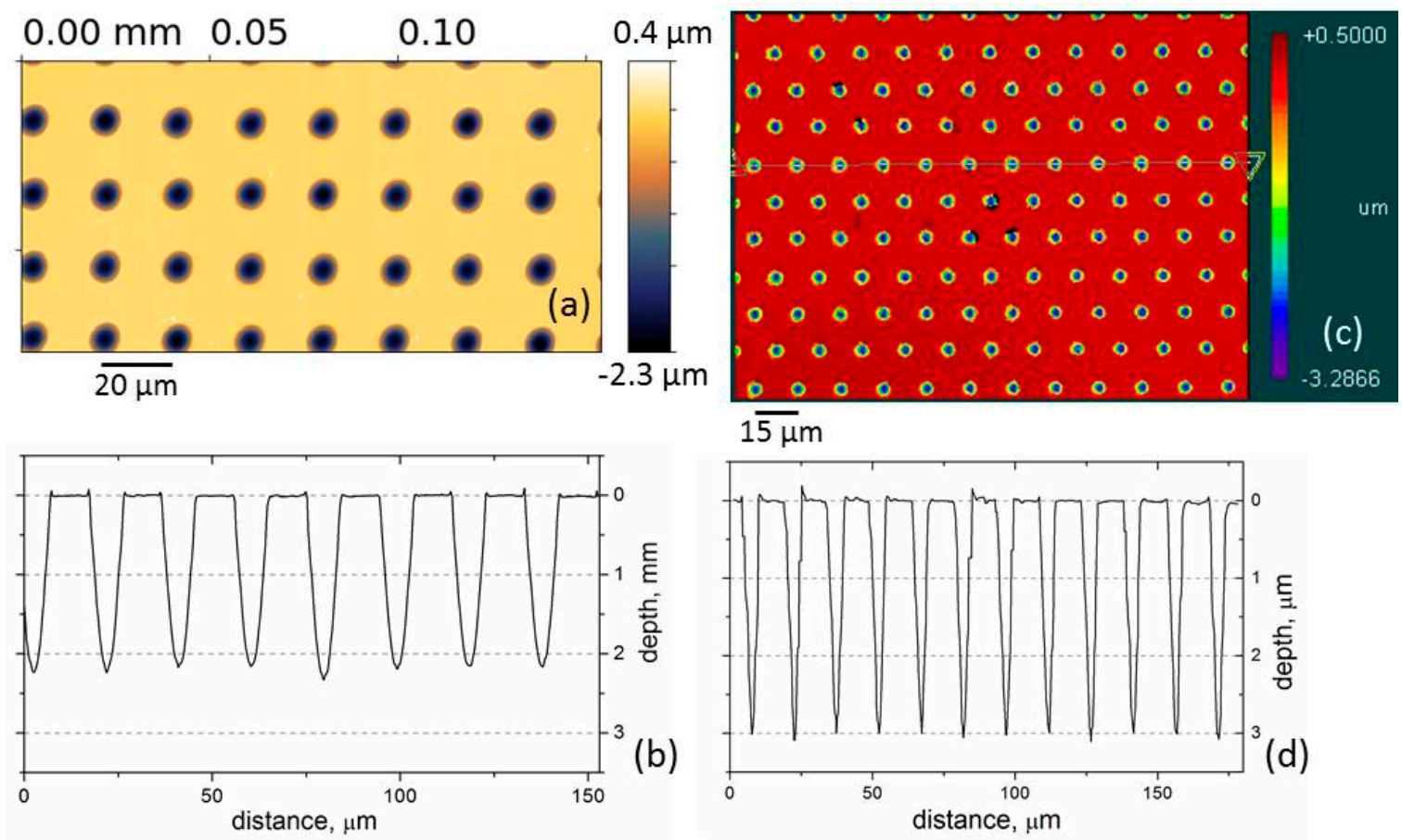

Figure 1. Femtosecond-laser produced surface micropatterns on DLN films of 3-5 $\mu \mathrm{m}$ thickness: (a,b) AFM image and surface profile of a microcrater array of "square" geometry (crater diameter $10 \mu \mathrm{m}$, depth $2.2 \mu \mathrm{m}$, and period $20 \mu \mathrm{m}$ ), $f=100 \mathrm{kHz}, \varepsilon=0.25 \mu \mathrm{J}, N=34$ pulses per crater; and (c,d) WLI image and surface profile of a microcrater array of hexagonal geometry (crater diameter $6 \mu \mathrm{m}$, depth $3 \mu \mathrm{m}$, and period $15 \mu \mathrm{m}$ ), $f=500 \mathrm{kHz}, \varepsilon=0.2 \mu \mathrm{J}, N=100$ repetitions per line.

To enhance the throughput of the fs-laser microprocessing, the second series was performed at $f=500 \mathrm{kHz}$, higher scanning velocities to obtain the period of $\Lambda=10-40 \mu \mathrm{m}$, 
and by making $N$ repetitions of the laser beam scanning along each line of microcraters in the $\mathrm{X}$ direction (to reach the required crater depth). The positioning accuracy of the scanning system provided the high-precision ablation of microcraters, thus allowing the heat accumulation effects [33] to be avoided at the high frequency because of increasing the time, from $1 / f=2 \mu \mathrm{s}$ to $l / V_{s} \sim 1 \mathrm{~ms}$ ( $l$ is the pattern length in the scanning direction), between each two successive pulses during ablation. The difference of the two scanning regimes/strategies in fabricating microcrater patterns was described in more detail in $[34,35]$. Using the high-frequency regime, the microcrater arrays of hexagonal geometry (shown in Figure 1c,d) are produced on DLN film surface areas of $10 \mathrm{~mm} \times 10 \mathrm{~mm}$ size. The AFM and WLI data in Figure 1 evidence highly precise and reproducible fabrication of microcrater arrays in thin DLN coatings. The surface structures of hexagonal geometry were used in the study of lubricated sliding properties of DLN coatings at different temperatures.

\section{Results and Discussion}

\subsection{Comparative Tribological Testing of DLN Films in Air and Water}

The comparative tribological tests in ambient air and distilled water were performed with the DLN films (on Si substrate) of $2.4 \mu \mathrm{m}$ thickness and high hardness $H=28 \mathrm{GPa}$ and elastic modulus $E=182 \mathrm{GPa}$, sliding against 100Cr6-steel $(H=8 \mathrm{GPa}, E=210 \mathrm{GPa})$ and $\mathrm{Si}_{3} \mathrm{~N}_{4}(H=15 \mathrm{GPa}, E=310 \mathrm{GPa})$ balls of $6 \mathrm{~mm}$-diameter. The use of the steel and ceramic balls was aimed at investigating the friction pair-dependent tribological behavior of the hard DLN films under water lubrication and specifics of the corrosive effect for DLN-steel tribological contacts which was not discussed in the early studies [8,9] of DLN films in water environment.

The friction behavior of the DLN films during sliding in humid air and under water is shown in Figure 2. For the load $F=0.5 \mathrm{~N}$ and ball radius $R_{b}=3 \mathrm{~mm}$, the mean contact pressure $(P)$, estimated from Hertz theory relationships [36], amounts to $P=0.35 \mathrm{GPa}$ and $0.37 \mathrm{GPa}$ for the DLN-steel and $\mathrm{DLN}-\mathrm{Si}_{3} \mathrm{~N}_{4}$ contacts at the beginning of sliding. As follows from Figure 2, the average values of the friction coefficient $\left(\mu_{\mathrm{av}}\right)$ in humid air are nearly the same for the two friction pairs: $\mu_{\mathrm{av}}=0.065$ for the DLN-steel and $\mu_{\mathrm{av}}=0.07$ for the DLN-Si ${ }_{3} \mathrm{~N}_{4}$. Under water lubrication the friction coefficient increases to $\mu_{\mathrm{av}}=0.14$ for both friction pairs. Some friction instabilities during sliding in water seem to be caused by water evaporation and varying thickness of the water layer. The comparative data of the wear tracks profiles and wear scars images are shown in Figure 3.

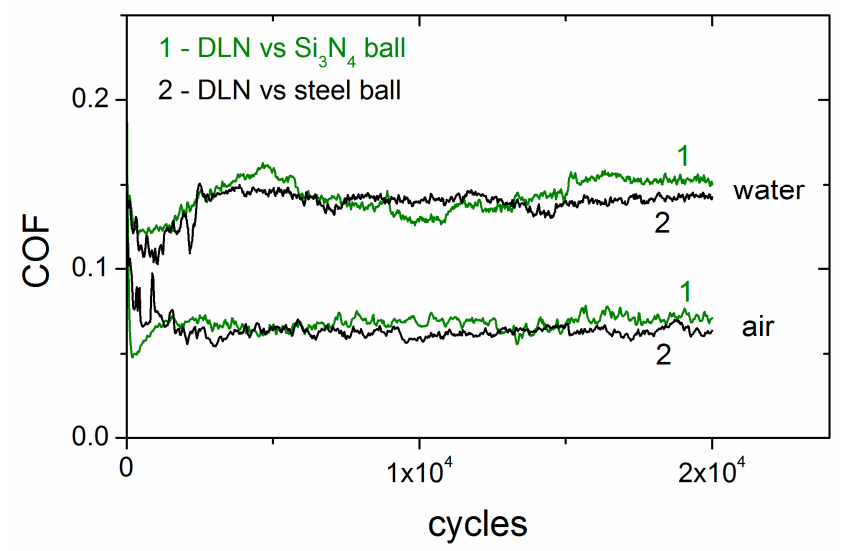

Figure 2. Friction performance of the DLN films during sliding against $100 \mathrm{Cr} 6$ steel and $\mathrm{Si}_{3} \mathrm{~N}_{4}$ balls in ambient air $(\mathrm{RH}=50 \%)$ and distilled water; the load $0.5 \mathrm{~N}$, the sliding speed $5 \mathrm{~cm} / \mathrm{s}$. 

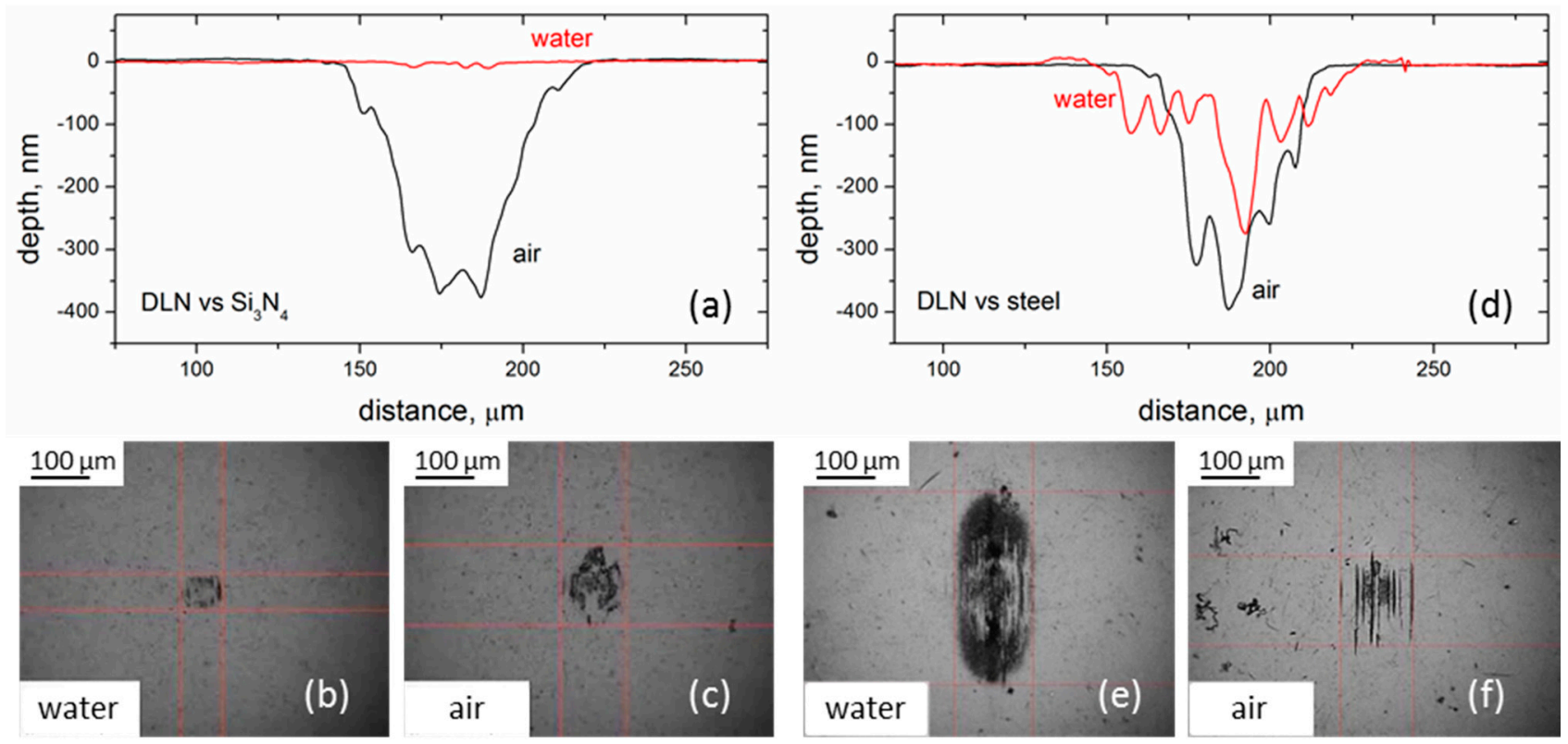

Figure 3. WLI surface profiles across the wear tracks (a,d) and OM images of the wear scars $(\mathbf{b}, \mathbf{c}, \mathbf{e}, \mathbf{f})$ on the ball surface formed after $2 \times 10^{4}$ cycles of $\mathrm{Si}_{3} \mathrm{~N}_{4}$ ball $(\mathbf{a}-\mathbf{c})$ and steel ball $(\mathbf{d}-\mathbf{f})$ sliding on the DLN films in humid air and in water.

Characteristics of the wear rates of the DLN film and ball surfaces in humid air and under water are summarized in Figure 4. The wear rate values are the averaged values of 2-3 tribotests performed for each sliding condition. The most pronounced effect of the aqueous environment on the wear behavior was observed in the sliding tests against the $\mathrm{Si}_{3} \mathrm{~N}_{4}$ ball, as shown in Figure 3a-c. The wear of the DLN film under water lubrication is very low compared to the friction tests in humid air, as directly follows from comparison of the wear track profiles in Figure 3a. The wear rate of the DLN film under water lubrication amounts to $\mathrm{W}=7.5 \times 10^{-9} \mathrm{~mm}^{3} /(\mathrm{Nm})$, two orders of magnitude lower than the wear rate $W=6.8 \times 10^{-7} \mathrm{~mm}^{3} /(\mathrm{Nm})$ of the film in humid air, see Figure 4 . In addition, the wear rate of the $\mathrm{Si}_{3} \mathrm{~N}_{4}$ ball under water lubrication, $\mathrm{W}=2.6 \times 10^{-9} \mathrm{~mm}^{3} /(\mathrm{Nm})$, is significantly lower than the wear rate $\mathrm{W}=3.8 \times 10^{-8} \mathrm{~mm}^{3} /(\mathrm{Nm})$ in ambient air. However, the friction coefficient $\mu_{\mathrm{av}}=0.14$ is twice higher in water-lubricated sliding, as shown in Figure 2. The observed inconsistency between the higher friction and low wear performance under water lubrication and the lower friction and high wear performance in humid air becomes understandable if the mechanism of friction in DLN films controlled by the transfer film formation $[11,12]$ is taken into consideration. For hydrogenated DLC films, the presence of graphitized transfer layers on the surface of counterface materials is known as one of major factors to influence the frictional behavior of the coatings $[37,38]$. Under water lubrication, the formation of the graphitized transfer film (responsible for the low friction in ambient air) is complicated because of the very low wear rate of the film surface, resulting in the increased friction during sliding. Note, the COF values during sliding in water were lower at higher loads [8,9], and strongly depended on the structure of Si-containing DLC films when tribochemical layers formation resulted in super low friction performance [39] (not observed in our experiments). In contrast to the $\mathrm{DLN}-\mathrm{Si}_{3} \mathrm{~N}_{4}$ friction pair, the wear characteristics of the DLN-steel pair were not improved in water-lubricated sliding. The wear rates of the DLN film were comparable in humid air and water environments: $\mathrm{W}=5 \times 10^{-7} \mathrm{~mm}^{3} /(\mathrm{Nm})$ and $\mathrm{W}=4.8 \times 10^{-7} \mathrm{~mm}^{3} /(\mathrm{Nm})$, respectively. The wear rate of the steel ball increased from the $\mathrm{W}=5.5 \times 10^{-8} \mathrm{~mm}^{3} /(\mathrm{Nm})$ in humid air to the $\mathrm{W}=2.8 \times 10^{-7} \mathrm{~mm}^{3} /(\mathrm{Nm})$ under water, which was caused by corrosion of steel known as a detrimental process for the DLC-steel contacts [40] in water environment. The observed friction and wear performance of the DLN films in water can be called superior compared to conventional a-C:H films which were reported to be quickly removed from the substrate during water-lubricated tests [40]. Generally, the obtained results have demonstrated the 
excellent tribological performance of the hard DLN films under water lubrication, in the absence of chemical interaction of water with the counterbody surface.

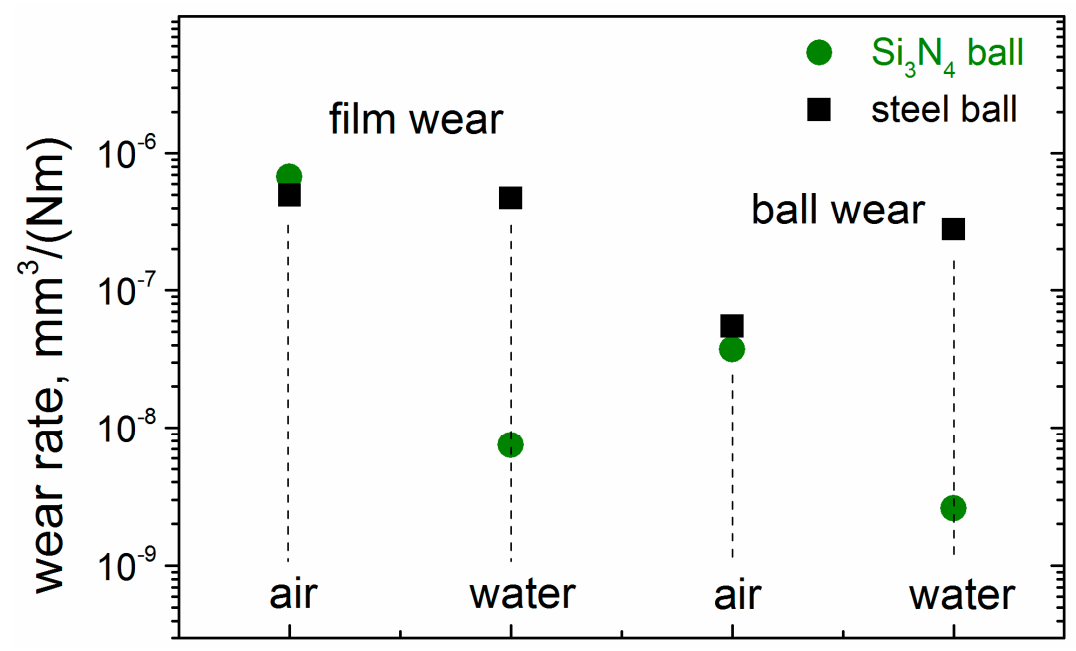

Figure 4. Wear rates of the DLN film and the ball surfaces in humid air and in water, measured after the friction tests shown in Figure 2.

\subsection{Lubricated Friction Performance of Laser-Textured DLN Films}

Tribological tests of laser-textured DLN films under oil lubrication were performed with the DLN-on-steel sample (film thickness $h=2.4 \mu \mathrm{m}$, hardness $H=14.7 \mathrm{GPa}$, elastic modulus $E=96 \mathrm{GPa}$ ) using a ball-on-disc tribometer. The optical microscopy image of the fs-laser-textured surface is shown in Figure 5 together with the WLI surface profiles of individual microcraters. The microcrater array of hexagonal geometry was produced over $10 \mathrm{~mm} \times 10 \mathrm{~mm}$ surface area at the average laser power $75 \mathrm{~mW}$ (frequency $f=500 \mathrm{kHz}$ ) and 100 repetitions of the scanning laser beam over each $10-\mathrm{mm}$ line along the $\mathrm{X}$ direction, taking in total $8.5 \mathrm{~min}$. The fabricated surface structure is characterized by the crater diameter $5 \mu \mathrm{m}$, depth $1.8 \mu \mathrm{m}$, and period $15 \mu \mathrm{m}$, which define the microcraters area density of $10 \%$.
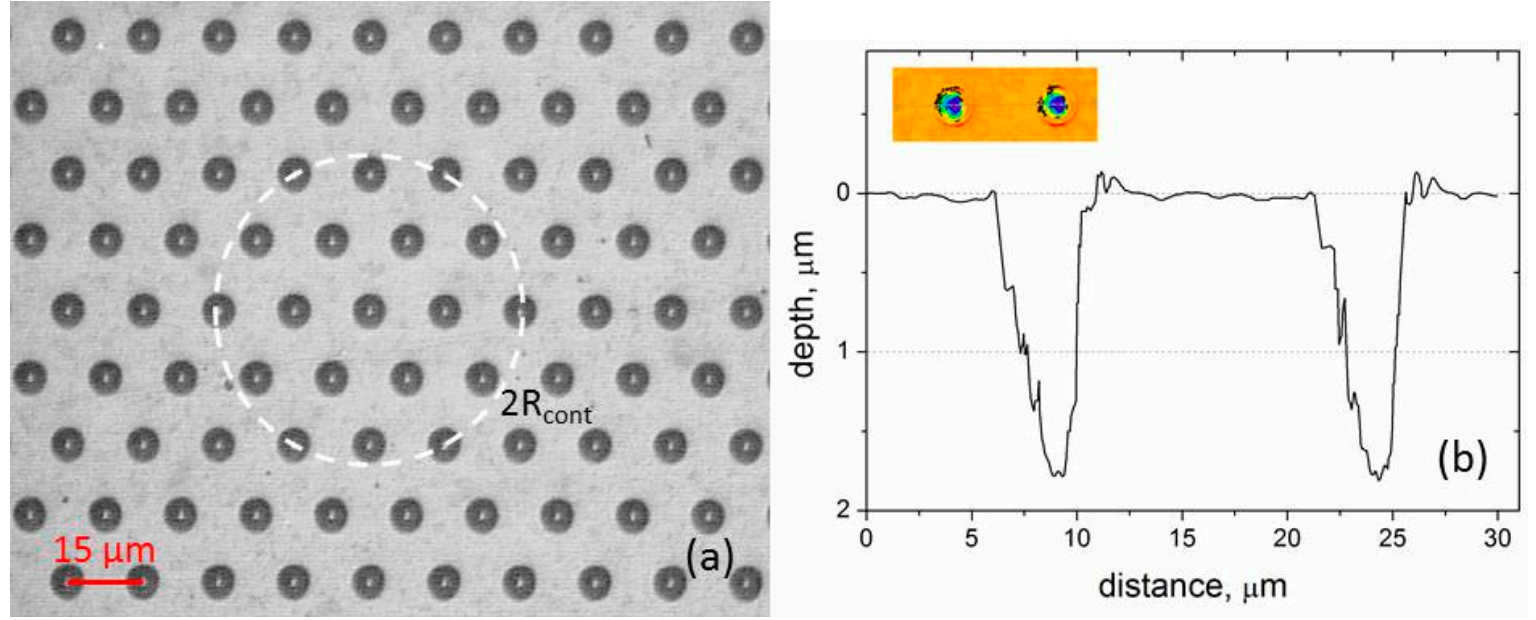

Figure 5. (a) OM image of the fs-laser-textured surface of the DLN film on steel substrate, and (b) WLI images and surface profiles of microcraters. The dashed circle with the diameter equal to $2 R_{\text {cont }}$ shows the contact area between the DLN film and $\mathrm{Si}_{3} \mathrm{~N}_{4}$ ball at the beginning of sliding. 
In order to see how the above structure parameters (crater diameter, period) correlate with the contact area between the DLN film and $\mathrm{Si}_{3} \mathrm{~N}_{4}$ ball, the radius of the contact area $\left(R_{\text {cont }}\right)$ was estimated using the known formula from theory of elasticity [36]

$$
R_{\text {cont }}=F^{1 / 3}\left\{0.75 \times\left[\left(1-v_{1}^{2}\right) / E_{1}+\left[\left(1-v_{2}^{2}\right) / E_{2}\right] \times R_{b}\right\}^{1 / 3}\right.
$$

and taking the values of Young's modulus and Poisson's ratio of the DLN film $\left(E_{1}=96 \mathrm{GPa}\right.$, $\left.v_{1}=0.3\right)$ and $\mathrm{Si}_{3} \mathrm{~N}_{4}$ ball $\left(E_{2}=310 \mathrm{GPa}, v_{2}=0.27\right)$, the load $F=1 \mathrm{~N}$ and ball radius $R_{b}=3 \mathrm{~mm}$. This gives the values of the radius $R_{\text {cont }}=30.4 \mu \mathrm{m}$ and mean contact pressure $P=F / \pi\left(R_{\text {cont }}{ }^{2}\right)$ $=344 \mathrm{MPa}$ at the beginning of sliding. The dashed circle, representing the contact area of the $2 R_{\text {cont }}$ diameter, is shown in Figure $5 \mathrm{a}$. It is seen that the contact area (of $\sim 61 \mu \mathrm{m}$ diameter) covers 4 periods of the patterned DLN film surface, corresponding to the non-conformal, relatively high-pressure contact during sliding [41].

Lubricated sliding performance of the laser-textured DLN film was studied at different temperature conditions: (i) at the room temperature $\mathrm{T}=23{ }^{\circ} \mathrm{C}$, (ii) at the temperature varied from $\mathrm{T}=23{ }^{\circ} \mathrm{C}$ to $\mathrm{T}=100{ }^{\circ} \mathrm{C}$, and (iii) at $\mathrm{T}=100{ }^{\circ} \mathrm{C}$. The first task was to study an influence of laser surface texturing on lubricated friction at the room temperature. The second task was to study an influence of the oil viscosity, changed with temperature from $v=945 \mathrm{~mm}^{2} / \mathrm{s}$ at $23^{\circ} \mathrm{C}$ to $v=20.4 \mathrm{~mm}^{2} / \mathrm{s}$ at $100{ }^{\circ} \mathrm{C}$, on the lubricated friction behavior of the laser-textured DLN surface at elevated temperatures close to engines operation conditions. A scheme of the lubricated friction measurements on the DLN sample with the laser-structured $10 \mathrm{~mm} \times 10 \mathrm{~mm}$ region in the center is shown in Figure 6a. The sequence of experiments was as follows: (i) lubricated sliding on the original film surface at $\mathrm{T}=23{ }^{\circ} \mathrm{C}$ and track radius $\mathrm{R}=7 \mathrm{~mm}$, (ii) lubricated sliding on the laser-textured surface at $\mathrm{T}=23^{\circ} \mathrm{C}$ and $\mathrm{R}=4.5 \mathrm{~mm}$, (iii) successive sliding tests on the laser-textured surface at the same track $\mathrm{R}=3 \mathrm{~mm}$, starting from $\mathrm{T}=23^{\circ} \mathrm{C}$ to continue at the varying temperature and finally at $\mathrm{T}=100^{\circ} \mathrm{C}$, and (iv) successive sliding tests repeated in a week at the same track ( $\mathrm{R}=3 \mathrm{~mm}$ ) and different temperatures. The sliding length $(L)$ was $L=20,000$ revolutions in the tests at constant temperature $\left(\mathrm{T}=23\right.$ and $\left.100^{\circ} \mathrm{C}\right)$, and $L=10,000$ revolutions at the varying temperature. The results of the lubricated friction tests of the original film and laser-textured surface at $\mathrm{T}=23{ }^{\circ} \mathrm{C}$ are presented in Figure $6 \mathrm{~b}$.
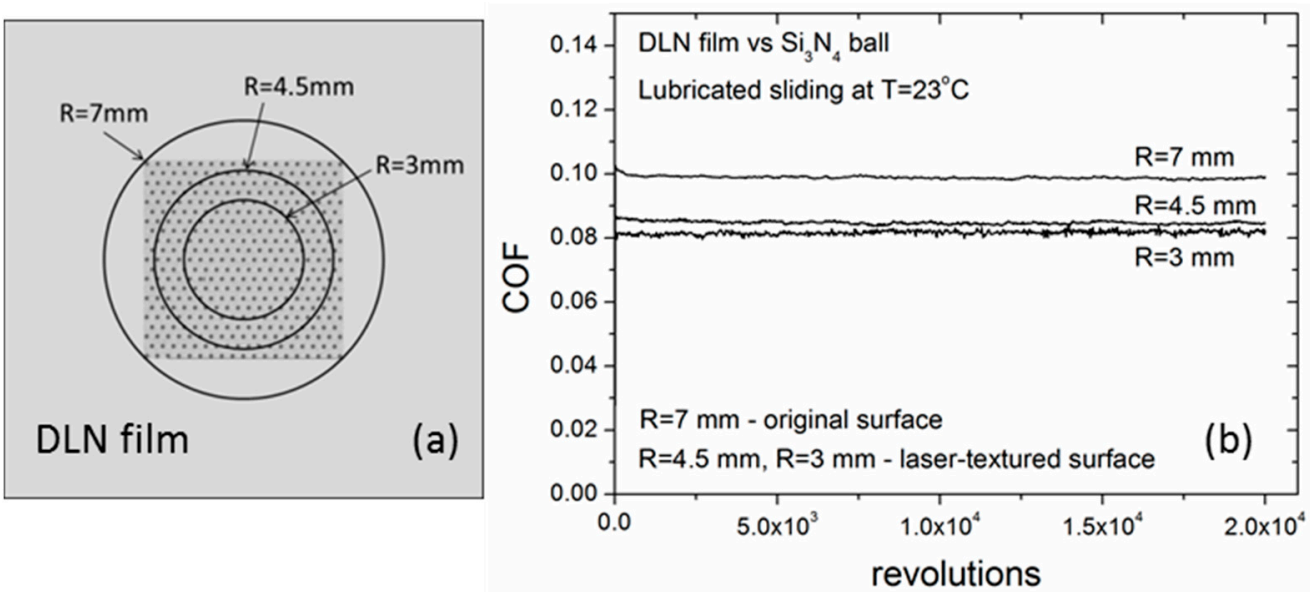

Figure 6. (a) Schematic of the friction measurements on the laser-textured DLN film, and (b) lubricated friction performance of the original film $(\mathrm{R}=7 \mathrm{~mm})$ and laser-textured $(\mathrm{R}=4.5 \mathrm{~mm}$ and $\mathrm{R}=3 \mathrm{~mm}$ ) surface at $\mathrm{T}=23{ }^{\circ} \mathrm{C}$; load $1 \mathrm{~N}$, sliding speed $5 \mathrm{~cm} / \mathrm{s}$.

Comparison of the friction curves in Figure $6 \mathrm{~b}$ shows the lower COF values for the laser-textured surface, $\mu_{\mathrm{av}}=0.085 \mathrm{at} \mathrm{R}=4.5 \mathrm{~mm}$ and $\mu_{\mathrm{av}}=0.081$ (averaged over two friction tests) at $\mathrm{R}=3 \mathrm{~mm}$, than the friction coefficient $\mu_{\mathrm{av}}=0.1$ for the original film. The WLI images of the wear tracks and surface profiles across the tracks, measured after removal of the oil film with n-heptane, are shown in Figure 7, which give information about the wear 
character of the DLN film surface during lubricated sliding. The depth of the wear tracks on the original film (Figure $7 \mathrm{a}, \mathrm{d}$ ) and laser-textured surface at $\mathrm{R}=4.5 \mathrm{~mm}$ (Figure $7 \mathrm{~b}, \mathrm{~d}$ ) is very small- $d_{t r}=19 \mathrm{~nm}$ and $d_{t r}=28 \mathrm{~nm}$, respectively. The difference of $\sim 10 \mathrm{~nm}$ in the track depth could be due to (i) a thin layer of ablated material on the laser-textured surface easily removed from the track area during sliding [26], or (ii) slightly increased wear because of protruding edges of microcraters. The width of both the tracks is about $w_{t r}=48 \mu \mathrm{m}$, smaller than the estimated value of the contact area diameter of $2 R_{\text {cont }} \sim 61 \mu \mathrm{m}$. The wear of the ball surface is also very small, which is pronounced in the appearance of individual scratches in the wear scars surface less discernible for the ball sliding on the original surface, as shown in Figure 8a,b. Under the observed low-wear rates of the film and ball counterparts the friction reduction on the laser-textured film (shown in Figure 6b) is due to lubricant film pressure lift in the mixed lubrication regime of sliding, consistent with our previous experiments with the microcrater patterns of higher area density $(20 \%$ and $40 \%$ ) and lubrication with synthetic motor oil of high viscosity [26]. Compared with the previous results [26], the influence of the relatively small (10\%) dimpled area density on the lubricated friction performance of the fs-laser-textured DLN films seems significant, implying that the texture optimization is needed for a given tribosystem used and for each particular application of laser-patterned DLC films.
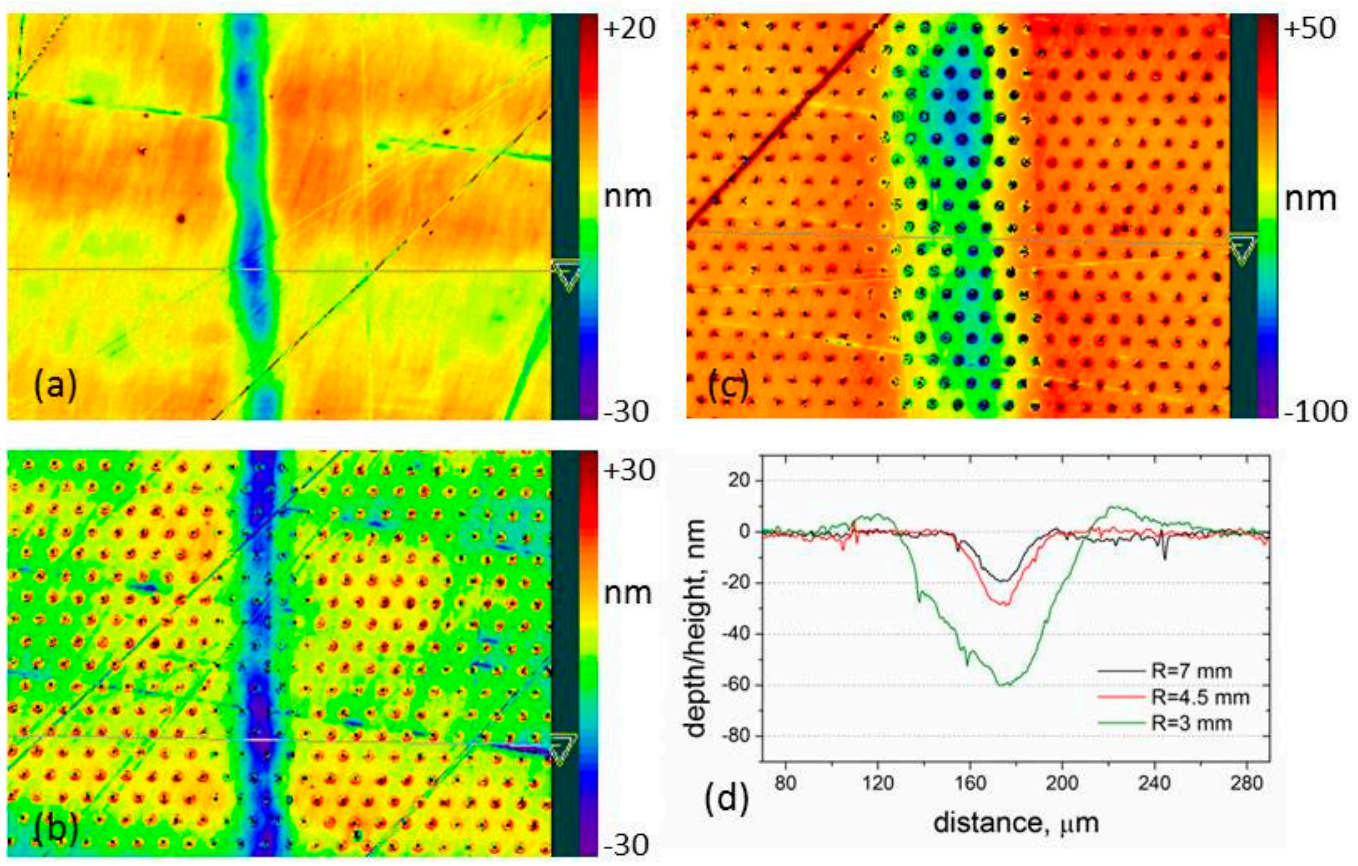

Figure 7. WLI images of the wear tracks formed on (a) the original film at $\mathrm{R}=7 \mathrm{~mm}$ and (b) lasertextured surface at $\mathrm{R}=4.5 \mathrm{~mm}$ after lubricated sliding at $\mathrm{T}=23^{\circ} \mathrm{C}$, and (c) after all the successive lubricated sliding tests of the laser-textured film at $\mathrm{R}=3 \mathrm{~mm}$ and different temperatures; (d) surface profiles across the tracks measured along the marked lines in the WLI images. 

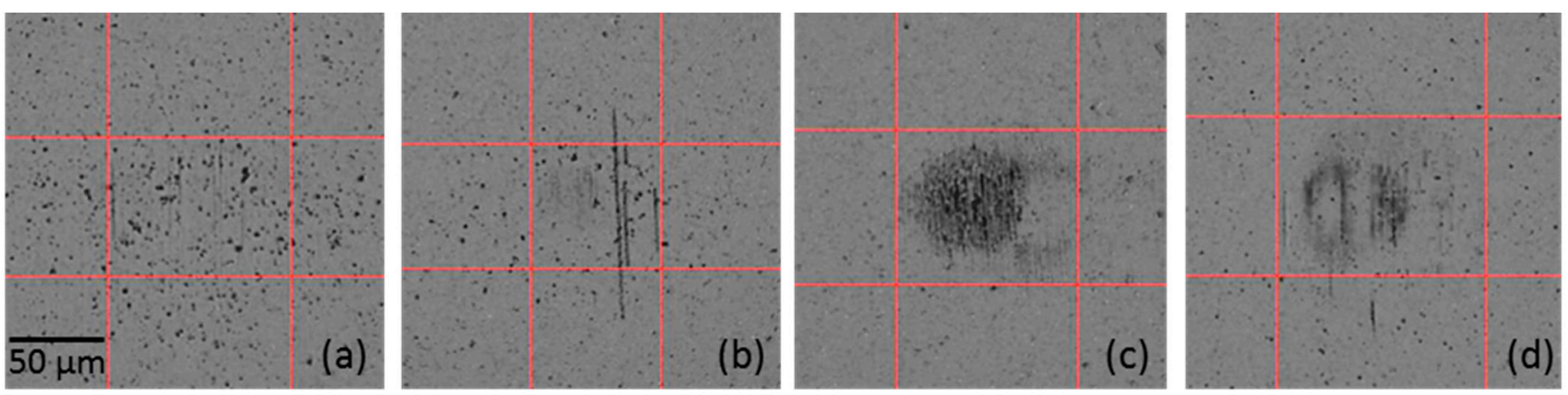

Figure 8. OM images of the wear scars on the $\mathrm{Si}_{3} \mathrm{~N}_{4}$ ball surface formed after lubricated sliding on: (a) the original surface at $\mathrm{T}=23^{\circ} \mathrm{C}, \mathrm{R}=7 \mathrm{~mm},(\mathbf{b})$ laser-textured surface at $\mathrm{T}=23^{\circ} \mathrm{C}, \mathrm{R}=4.5 \mathrm{~mm},(\mathbf{c})$ laser-textured surface at $\mathrm{R}=3 \mathrm{~mm}$ in the first series of the successive tests at different temperatures, and (d) in the repeated tests at $\mathrm{R}=3 \mathrm{~mm}$ at different temperatures.

The results of lubricated friction tests of the laser-textured film at elevated temperatures are presented in Figure 9. An interesting temperature-dependent friction behavior was observed in the course of the sample heating from $\mathrm{T}=23^{\circ} \mathrm{C}$ to $\mathrm{T}=100{ }^{\circ} \mathrm{C}$ (Figure 9a). Figure 9a shows the gradual change of the temperature from $\mathrm{T}=23^{\circ} \mathrm{C}$ to $\mathrm{T}=100^{\circ} \mathrm{C}$ and corresponding changes of the friction coefficient during lubricated sliding at variable oil viscosity, with the friction curves $\mu(1)$ and $\mu(2)$ relating to two tribotests carried out on the same sliding track with the time gap of one week. The data of the oil viscosity vs temperature [29] is replotted vs sliding distance and shown by a dashed curve. A principal difference between the two tests, marked as the $\mu(1)$ and $\mu(2)$ curves, is that the second test starts on the already formed wear track, similar but less deep than the wear track in Figure 7c. At the beginning of the lubricated tests, the friction coefficient increases with temperature from $\mu=0.09-0.095$ at room temperature to $\mu=0.11$ at $\mathrm{T} \approx 90^{\circ} \mathrm{C}$ and $L \sim 3.5 \times 10^{3}$ revolutions for both $\mu(1)$ and $\mu(2)$ curves. Then the $\mu(1)$ continues to increase to $\mu=0.12$ at $\mathrm{T}=107^{\circ} \mathrm{C}$ and $L=6 \times 10^{3}$ revolutions, followed by a gradual decrease to the $\mu=0.095$ when the sample temperature is stabilized at $\mathrm{T}=100^{\circ} \mathrm{C}$. In contrast, the $\mu(2)$ decreases and stabilizes at the level of $\mu=0.1$, starting to decrease again at the end of the test. In the continued sliding tests at $\mathrm{T}=100{ }^{\circ} \mathrm{C}$ (which were restarted in a few minutes after the tests in Figure $9 \mathrm{a}$, the $\mu(1)$ is decreased to $\mu=0.073$ (averaged over $2 \times 10^{4}$ revolutions) and the $\mu(2)$ is decreased to even lower value of $\mu=0.068$, as shown in Figure $9 b$.
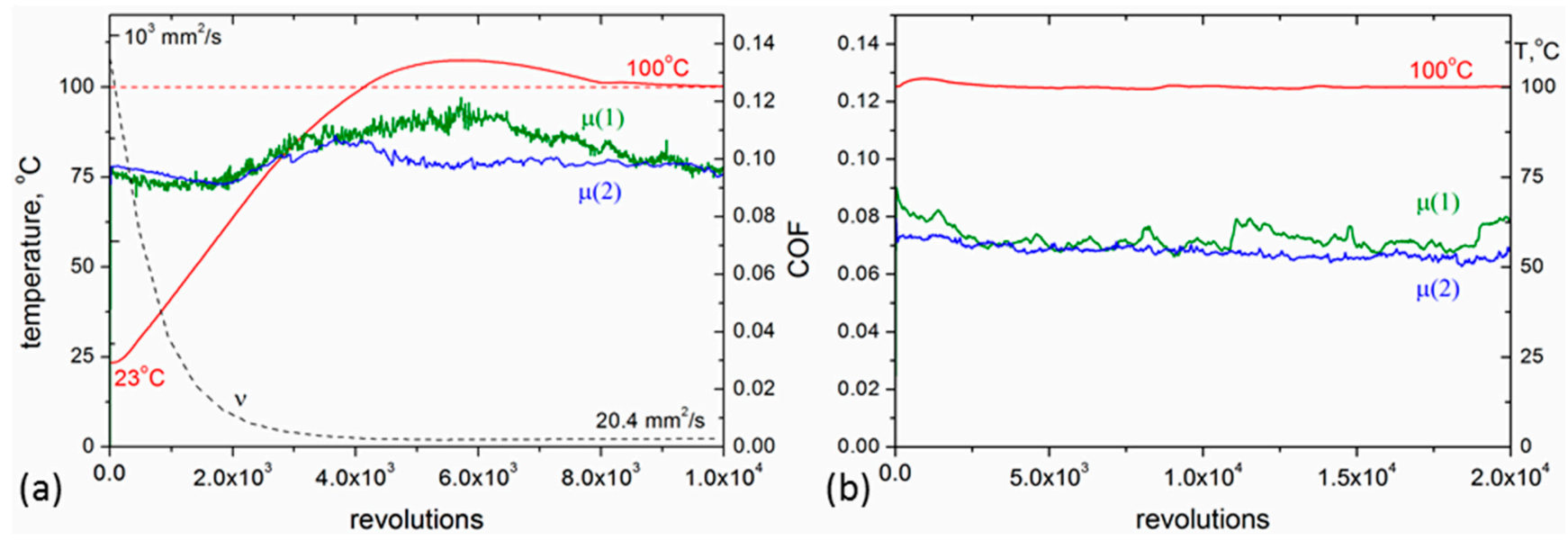

Figure 9. (a) Change in the temperature of the DLN sample during heating from $\mathrm{T}=23{ }^{\circ} \mathrm{C}$ to $\mathrm{T}=100{ }^{\circ} \mathrm{C}$ and corresponding change of the friction coefficient in the two tests of lubricated sliding on the laser-textured film; the oil viscosity data (taken from [29]) replotted vs sliding distance is shown by a dashed curve. (b) Lubricated friction performance of the laser-textured film at $\mathrm{T}=100{ }^{\circ} \mathrm{C}$; load $1 \mathrm{~N}$, sliding speed $5 \mathrm{~cm} / \mathrm{s}$. Two series of the successive lubricated sliding tests, corresponding to the friction curves $\mu(1)$ and $\mu(2)$ in both (a) and (b), were made at the same sliding track of $R=3 \mathrm{~mm}$. 
The initial rise of the friction coefficient with temperature for both $\mu(1)$ and $\mu(2)$ curves is mainly caused by the decrease in the oil viscosity (with temperature), which is known to result in reduced thickness of the lubricant film and higher friction $[42,43]$. The fact of the identical friction behavior (in the range from $L=0$ to $3.5 \times 10^{3}$ revolutions) on the original textured surface of higher roughness and the track surface smoothed during the first sliding test clearly supports the above reasoning. As soon as the oil viscosity (and lubricant film thickness) is strongly reduced, the roughness factor, dealing with swelling edges of microcraters, becomes chiefly responsible for the increase of the friction coefficient in the $\mu(1)$ curve at $3.5 \times 10^{3}<L<6 \times 10^{3}$ revolutions. While for the smoothed surface, the friction reduction and subsequent stabilization at $\mathrm{T}>90^{\circ} \mathrm{C}$ and $L>3.5 \times 10^{3}$ revolutions in the $\mu(2)$ curve (in Figure 9a) is controlled by the balance between high stresses generated around microcraters in the contact area, acting as "artificial" roughness, and lubricant film pressure lift in the non-conformal sliding contact $[41,44]$. An additional important parameter is an increasing wear of the ball, which leads to a gradual increase in the contact area, transition from the boundary to the mixed lubrication regime, and to the friction reduction [42].

The data of the wear character of the film and ball surfaces during lubricated sliding at elevated temperatures are shown in Figure $7 \mathrm{c}, \mathrm{d}$ and Figure $8 \mathrm{c}, \mathrm{d}$. The wear track at $\mathrm{R}=3 \mathrm{~mm}$, shown in Figure 7c, was formed after all the successive lubricated sliding tests of the laser-textured film at different temperatures, giving information about the total effect of the six sliding tests on the wear of the film surface. This total effect is pronounced in the increased width $w_{t r}=83 \mu \mathrm{m}$ and depth $d_{t r}=60 \mathrm{~nm}$ of the wear track at $\mathrm{R}=3 \mathrm{~mm}$ compared to the wear track at $\mathrm{R}=4.5 \mathrm{~mm}$ formed during sliding at $\mathrm{T}=23{ }^{\circ} \mathrm{C}$. The images of the wear scars indicate the increased wear of the ball after each of two lubrication tests at elevated temperatures. It is the lubricated sliding at elevated temperatures which results in the increased wear of the ball, due to a strongly reduced thickness of the lubricant film. So the friction reduction at $\mathrm{T}=100{ }^{\circ} \mathrm{C}$, shown in Figure $9 \mathrm{a}, \mathrm{b}$, is controlled by the total effect of high stresses at the crater edges ("artificial" roughness), lubricant film pressure lift, and wear of the ball, characteristic of the mixed lubrication regime of sliding. It is also important to note that the adhesion of the laser-texture film to steel substrate is sufficiently high to provide the low-friction performance of the film under oil lubrication at $\mathrm{T}=100{ }^{\circ} \mathrm{C}$, typical of the engine's operation conditions in harsh environment. To conclude, the laser-textured DLN coatings on steel, with the surface micropattern characterized by high-symmetry hexagonal geometry and small (10\%) dimpled area density, have demonstrated excellent tribological properties under oil lubrication and elevated temperatures. The lubricated friction performance of the laser-textured films has been improved at room temperature, compared to the original non-patterned surface, and elevated temperatures.

\subsection{Nano/Microfriction Behavior of Laser-Textured DLN Films}

The nano-/microfriction behavior of laser-textured DLN films was studied using contact-mode AFM techniques, including lateral force microscopy (LFM) and force-distance curve measurements. The LFM technique allows the surface relief and lateral (friction) force images to be measured simultaneously during tip scanning [45,46], and for relatively large scanning regions (from $20 \mu \mathrm{m} \times 20 \mu \mathrm{m}$ to $160 \mu \mathrm{m} \times 160 \mu \mathrm{m}$ ) it enables the friction forces to be determined in laser-patterned and original surface areas of DLC films. Measurements of the force-distance curves $[47,48]$ are used to determine the capillary forces between the AFM tip and film surface on the laser-patterned and non-patterned regions. These contact-mode AFM methods were applied to study the nano and microscale friction properties of laser-produced microgrooves on DLN films, described in detail in refs. [16,25]. In this paper, the AFM techniques are used to examine the surface properties of the laserstructured surface area consisting of microcraters, particularly, the laser-structured film shown in Figure 1a.

The surface relief and friction force (FF) images of the laser-patterned DLN film are shown in Figure 10. A region near the corner of the microcrater structure was examined 
to compare the friction forces on the original and laser-patterned DLN surface. Similar to the previous studies [25], the LFM imaging was carried out using worn Si tips with the tip radius of $0.5-1 \mu \mathrm{m}$. The friction contrast is clearly seen and characterized by considerably lower friction forces in the laser-patterned region than on the original surface, see Figure 10b. Because of relatively deep craters, the contribution of the surface relief slope to the lateral force signal is not fully compensated during subtraction of two lateral force images [46], leading to "higher friction" at the crater edges.

The lower friction forces in the laser-patterned region are accompanied with much lower pull-off forces $\left(F_{\text {pull-off }}\right)$ than on the original film, as confirmed by the force-distance curves (Figure 11a) measured in different positions in the FF image in Figure 10b, namely: (1) $F_{\text {pull-off }}=1290 \mathrm{nN}$ on the original film, (2) $F_{\text {pull-off }}=990 \mathrm{nN}$ near the region of redeposited material, (3) $F_{\text {pull-off }}=63 \mathrm{nN}$ in the region of redeposited material, and (4) $F_{\text {pull-off }}=16 \mathrm{nN}$ in the center of a crater. This means that the ablated and redeposited material changes the nanoscale surface properties within and around the laser-produced microcraters. The area of the low-friction region with redeposited material covers the distance of 10-12 $\mu \mathrm{m}$ from the crater edge and, including the crater, it covers a circle area of $15-17 \mu \mathrm{m}$ radius. The occurrence of the region " 2 " with slightly lower friction and pull-off force (than on original surface) is probably caused by mass distribution of ablated clusters/particles, leading to variation in the structure and/or thickness of the redeposited layer.
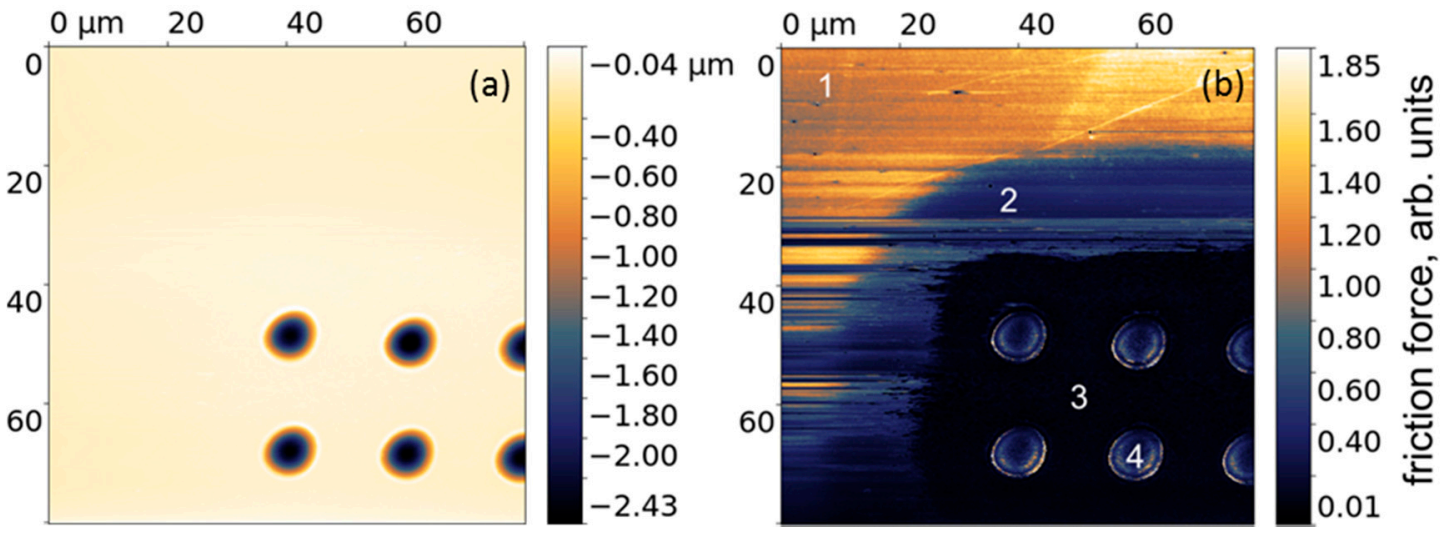

Figure 10. Surface relief (a) and friction force (b) images of the laser-patterned DLN film near the corner of a microcrater structure (shown in Figure 1a), load on Si tip $120 \mathrm{nN}$. The marked points $(1,2,3,4)$ in the FF image are the places of force-distance curves measurements, shown in Figure 11.
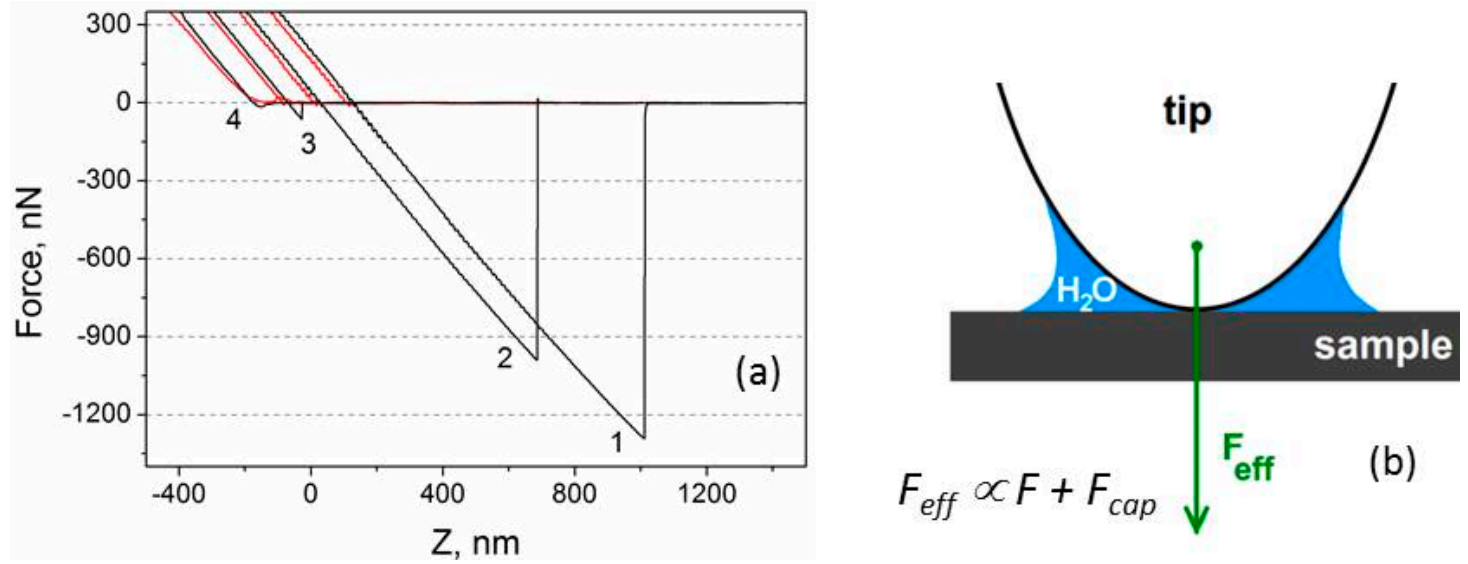

Figure 11. (a) The force-distance curves measured in different points on the DLN film (marked in the FF image in Figure 10b): (1) original film, (2) near the region of redeposited material, (3) in the region of redeposited material, (4) in the center of a crater, and (b) schematic of the capillary force action on Si tip. 
In the case of humid atmosphere, hydrophilic surfaces, and large tip radius (hundreds $\mathrm{nm}$ and more), the dominant component of the pull-off force is the capillary force $\left(F_{\text {cap }}\right)$ caused by the Laplace pressure in a water meniscus formed between the tip and film surface [49-51], i.e., $F_{\text {pull-off }} \approx F_{\text {cap }}$. As follows from the force-distance curves, the capillary force is changed by $1-2$ orders of magnitude from $\sim 1300 \mathrm{nN}$ on the original film to $16-63 \mathrm{nN}$ on the laser-structured surface of the DLN films. At the very light loads on the tips $(F \sim 120 \mathrm{nN})$ during LFM measurements, the real loads on micro-sized Si tips become much larger on the original film $(F=1410 \mathrm{nN})$ than on the fs-laser-modified surface $(F=136-183 \mathrm{nN})$ due to the action of the capillary force, schematically shown in Figure 11b. So the observed friction contrast in the FF image (Figure 10b) is caused by the large difference between the real tip loads on the DLN surface regions with different surface properties. For the regions between microcraters (marked as point " 3 " in Figure 10b), the surface properties are defined by a thin layer of nanoparticles of the redeposited material, the thickness of which depends on the fs-laser surface structuring conditions: 50-100 nm thick for microgrooves patterns $[25,27]$ and $\sim 20 \mathrm{~nm}$ thick for microcrater arrays [26]. The contact angle measurements evidenced that the fs-laser-modified surface remained hydrophilic (although more hydrophobic than the original DLN surface), so the nanoscale surface roughness was suggested to be a major factor accounting for the huge difference in the pull-off and capillary forces $[25,27]$. The nanoscale surface roughness was reported to increase from $R_{a}=0.6 \mathrm{~nm}$ on the original surface to $R_{a}=3 \mathrm{~nm}$ on the surface regions between microcraters [26]. The higher roughness results in smaller areas of water menisci formed between the Si tip and film surface and, therefore, to lower capillary and friction forces in the laser-patterned areas [25]. This reveals an unusual interrelation between the friction and roughness occurring at the nano/microscale, when the lower friction corresponds to the higher roughness, opposite to the friction-on-roughness dependence at the macroscale. For the microcrater pattern shown in Figures 1a and 10, the effect seems to be even more surprising than for the microgroove patterns because of a significantly thinner layer of nanoparticles formed during fs-laser processing. These findings are of great interest in fundamental nanotribological studies of carbon-based films [52], and they clearly demonstrate the efficiency of fs-laser ablation processing of DLN films to control the nano-/microfriction behavior of the hard coatings with potential applications in micro/nanoelectromechanical systems and small-scale devices operating in humid air environments.

\section{Conclusions}

Tribological properties of the DLN coatings deposited on silicon and steel substrates have been studied under various conditions influenced by environments (humid air, water and oil lubrication, elevated temperatures) and laser surface texturing. Comparative tribological tests of hard DLN films in humid air and under water sliding against different counterbodies (steel, silicon-nitride) have demonstrated the low-friction and low-wear performance of the films under water lubrication, in the absence of chemical interaction of water with the counterbody surface. A strong impact of the aqueous environment on the wear behavior was revealed for the $\mathrm{DLN} / \mathrm{Si}_{3} \mathrm{~N}_{4}$ tribopair: the wear rates of the film and $\mathrm{Si}_{3} \mathrm{~N}_{4}$ ball in water, $\mathrm{W}=7.5 \times 10^{-9} \mathrm{~mm}^{3} /(\mathrm{Nm})$ and $\mathrm{W}=2.6 \times 10^{-9} \mathrm{~mm}^{3} /(\mathrm{Nm})$, were found to be considerably lower than the corresponding values $W=6.8 \times 10^{-7} \mathrm{~mm}^{3} /(\mathrm{Nm})$ and $W=3.8 \times 10^{-8} \mathrm{~mm}^{3} /(\mathrm{Nm})$ in humid air, in spite of higher friction in water-lubricated sliding. Particular attention in this work has been paid to the high-precision surface texturing of DLN films with femtosecond-laser pulses and fabrication of microcrater-based structures of hexagonal geometry, followed by tribological testing of the laser-textured DLN samples under oil lubrication at different temperatures, from 23 to $100{ }^{\circ} \mathrm{C}$. The influence of laser surface texturing is found in the improved friction performance at both the room temperature (compared to the original films) and elevated temperatures, when the oil viscosity changed from $v=945 \mathrm{~mm}^{2} / \mathrm{s}$ at $23^{\circ} \mathrm{C}$ to $v=20.4 \mathrm{~mm}^{2} / \mathrm{s}$ at $100{ }^{\circ} \mathrm{C}$ (mineral oil MS20). The friction coefficient was reduced from $\mu_{\mathrm{av}}=0.1$ for the original film to $\mu_{\mathrm{av}}=0.083$ 
for the laser-textured surface at room temperature, and then to $\mu_{\mathrm{av}}=0.068$ at $100{ }^{\circ} \mathrm{C}$. The obtained results evidence that the friction reduction at elevated temperatures is controlled by the total effect of high stresses at the crater edges ("artificial" roughness), lubricant film pressure lift, and wear of the counterbody, characteristic of the mixed lubrication regime of sliding. In addition to the macroscale friction studies of the laser-textured films, it is shown that the nano-/microfriction behavior of the microcrater-based surface structure is characterized by considerably lower friction forces than the original surface due to strong influence of the capillary forces on friction forces in humid air environment. The findings of this work evidence about excellent tribological properties of the DLN coatings in various environments, which can be further improved by high-precision surface texturing with femtosecond-laser pulses.

Author Contributions: S.M.P.: writing—original draft preparation, writing—reviewing and editing, project administration; E.V.Z.: investigation; O.S.Z.: investigation, methodology; A.P.L.: investigation; B.J.: investigation; B.N.: investigation, methodology. All authors have read and agreed to the published version of the manuscript.

Funding: This work was supported by the Russian Science Foundation [project No.15-12-00039].

Institutional Review Board Statement: Not applicable.

Informed Consent Statement: Not applicable.

Data Availability Statement: Not applicable.

Acknowledgments: The authors thank Mikhail Shupegin for DLN film deposition, and Vladimir Samusenko for giving the MS-20 oil used in lubricated sliding experiments.

Conflicts of Interest: The authors declare no conflict of interest.

\section{References}

1. Dorfman, V.F. Diamond-like nanocomposites (DLN). Thin Solid Films 1992, 212, 267-273. [CrossRef]

2. Dorfman, V.F.; Pypkin, B.N. Amorphous solid systems: Diamond-like carbon, carbides, films and multilayer structures. Surf. Coat. Technol. 1991, 48, 193-198. [CrossRef]

3. Meškinis, Š.; Tamulevičienè, A. Structure, properties and applications of diamond like nanocomposite $\left(\mathrm{SiO}_{x}\right.$ containing DLC) films: A review. Mater. Sci. (Medžiagotyra) 2011, 17, 358-370.

4. Yang, W.J.; Choa, Y.H.; Sekino, T.; Shim, K.B.; Niihara, K.; Auh, K.H. Thermal stability evaluation of diamond-like nanocomposite coatings. Thin Solid Films 2003, 434, 49-54. [CrossRef]

5. Mangolini, F.; McClimon, J.B.; Segersten, J.; Hilbert, J.; Heaney, P.; Lukes, J.R.; Carpick, R.W. Silicon oxide-rich diamond-like carbon: A conformal, ultrasmooth thin film material with high thermo-oxidative stability. Adv. Mater. Interfaces 2018, 1801416. [CrossRef]

6. Grenadyorov, A.S.; Solovyev, A.A.; Oskomov, K.V.; Oskirko, V.O.; Semenov, V.A. Thermal stability of anti-reflective and protective a-C:H:SiO $x$ coating for infrared optics. Appl. Surf. Sci. 2020, 510, 145433. [CrossRef]

7. Pimenov, S.M.; Zavedeev, E.V.; Arutyunyan, N.R.; Zilova, O.S.; Presniakov, M.Y.; Barinov, A.D.; Shupegin, M.L. Effects of titanium doping on the structure and mechanical properties of diamond-like nanocomposite films. Surf. Coat. Technol. 2020, $402,126300$. [CrossRef]

8. Neerinck, D.; Persoone, P.; Sercu, M.; Goel, A.; Venkatraman, C.; Kester, D.; Halter, C.; Swab, P.; Bray, D. Diamond-like nanocomposite coatings for low-wear and low-friction applications in humid environments. Thin Solid Films 1998, 317, 402-404. [CrossRef]

9. Neerinck, D.; Persoone, P.; Sercu, M.; Goel, A.; Kester, D.; Bray, D. Diamond-like nanocomposite coatings (a-C:H/a-Si:O) for tribological applications. Diam. Relat. Mater. 1998, 7, 468-471. [CrossRef]

10. Kester, D.J.; Brodbeck, C.L.; Singer, I.L.; Kyriakopoulos, A. Sliding wear behavior of diamond-like nanocomposite coatings. Surf. Coat. Technol. 1999, 113, 268-273. [CrossRef]

11. Scharf, T.W.; Singer, I.L. Monitoring transfer films and friction instabilities with in situ Raman tribometry. Tribol. Lett. 2003, 14, 3-8. [CrossRef]

12. Scharf, T.W.; Ohlhausen, J.A.; Tallant, D.R.; Prasad, S.V. Mechanisms of friction in diamondlike nanocomposite coatings. J. Appl. Phys. 2007, 101, 063521. [CrossRef]

13. Yang, W.J.; Sekino, T.; Shim, K.B.; Niihara, K.; Auh, K.H. Microstructure and tribological properties of $\mathrm{SiO}_{x} / \mathrm{DLC}$ films grown by PECVD. Surf. Coat. Technol. 2005, 194, 128-135. [CrossRef]

14. Santra, T.S.; Liu, C.H.; Bhattacharyya, T.K.; Patel, P.; Barik, T.K. Characterization of diamond-like nanocomposite thin films grown by plasma enhanced chemical vapor deposition. J. Appl. Phys. 2010, 107, 124320. [CrossRef] 
15. Koshigan, K.; Mangolini, F.; McClimon, J.B.; Vacher, B.; Bec, S.; Carpick, R.W.; Fontaine, J. Understanding the hydrogen and oxygen gas pressure dependence of the tribological properties of silicon oxide-doped hydrogenated amorphous carbon coatings. Carbon 2015, 93, 851-860. [CrossRef]

16. Pimenov, S.M.; Zavedeev, E.V.; Arutyunyan, N.R.; Zilova, O.S.; Shupegin, M.L.; Jaeggi, B.; Neuenschwander, B. Femtosecond-laser surface modification and micropatterning of diamond-like nanocomposite films to control friction on the micro and macroscale. J. Appl. Phys. 2017, 122, 145301. [CrossRef]

17. McClimon, J.B.; Lang, A.C.; Milne, Z.; Garabedian, N.; Moore, A.C.; Hilbert, J.; Mangolini, F.; Lukes, J.R.; Burris, D.L.; Taheri, M.L.; et al. Investigation of the mechanics, composition, and functional behavior of thick tribofilms formed from silicon- and oxygen-containing hydrogenated amorphous carbon. Tribol. Lett. 2019, 67, 48. [CrossRef]

18. Grenadyorov, A.S.; Oskirko, V.O.; Solovyev, A.A.; Oskomov, K.V.; Khlusov, I.A. Wear and corrosion resistance of a-C:H:SiO $x$ coating on medical 316L stainless steel. J. Mater. Eng. Perform. 2021, 30, 1099-1110. [CrossRef]

19. Zavedeev, E.V.; Zilova, O.S.; Shupegin, M.L.; Barinov, A.D.; Arutyunyan, N.R.; Roch, T.; Pimenov, S.M. Effects of UV laser micropatterning on frictional performance of diamond-like nanocomposite films. Appl. Phys. A 2016, 122, 961. [CrossRef]

20. Zavedeev, E.V.; Zilova, O.S.; Barinov, A.D.; Shupegin, M.L.; Arutyunyan, N.R.; Jaeggi, B.; Neuenschwander, B.; Pimenov, S.M. Femtosecond laser microstructuring of diamond-like nanocomposite films. Diam. Relat. Mater. 2017, 74, 45-52. [CrossRef]

21. Dumitru, G.; Romano, V.; Weber, H.P.; Pimenov, S.; Kononenko, T.; Hermann, J.; Bruneau, S.; Gerbig, Y.; Shupegin, M. Laser treatment of tribological DLC films. Diam. Relat. Mater. 2003, 12, 1034-1040. [CrossRef]

22. Pettersson, U.; Jacobson, S. Friction and wear properties of micro textured DLC coated surfaces in boundary lubricated sliding. Tribol. Lett. 2004, 17, 553-559. [CrossRef]

23. Ding, Q.; Wang, L.; Wang, Y.; Wang, S.C.; Hu, L.; Xue, Q. Improved tribological behavior of DLC films under water lubrication by surface texturing. Tribol. Lett. 2011, 41, 439-449. [CrossRef]

24. Shum, P.W.; Zhou, Z.F.; Li, K.Y. Investigation of the tribological properties of the different textured DLC coatings under reciprocating lubricated conditions. Tribol. Int. 2013, 65, 259-264. [CrossRef]

25. Zavedeev, E.V.; Jaeggi, B.; Zuercher, J.; Neuenschwander, B.; Zilova, O.S.; Shupegin, M.L.; Presniakov, M.Y.; Pimenov, S.M. Effects of AFM tip wear on frictional images of laser-patterned diamond-like nanocomposite films. Wear 2018, 416-417, 1-5. [CrossRef]

26. Pimenov, S.M.; Jaeggi, B.; Neuenschwander, B.; Zavedeev, E.V.; Zilova, O.S.; Shupegin, M.L. Femtosecond laser surface texturing of diamond-like nanocomposite films to improve tribological properties in lubricated sliding. Diam. Relat. Mater. 2019, 93, 42-49. [CrossRef]

27. Pimenov, S.M.; Zavedeev, E.V.; Arutyunyan, N.R.; Presniakov, M.Y.; Zilova, O.S.; Shupegin, M.L.; Jaeggi, B.; Neuenschwander, B Femtosecond-laser-ablation induced transformations in the structure and surface properties of diamond-like nanocomposite films. Appl. Surf. Sci. 2020, 509, 144907. [CrossRef]

28. GOST 21743-76. Aviation oils. Specifications. Available online: https://gosthelp.ru/gost/gost34175.html (accessed on 20 September 2021). (In Russian)

29. Ivanov, V.S.; Fridman, S.M. Oils and Lubricants for Power Engineering. In Chemist-Power Engineer Handbook, 2nd ed.; Energy: Moscow, Russia, 1972; Volume 2, p. 31. (In Russian)

30. Neuenschwander, B.; Jaeggi, B.; Schmid, M.; Hennig, G. Surface structuring with ultra-short laser pulses: Basics, limitations and needs for high throughput. Phys. Procedia 2014, 56, 1047-1058. [CrossRef]

31. Jaeggi, B.; Neuenschwander, B.; Remund, S.; Kramer, T. Influence of the pulse duration and the experimental approach onto the specific removal rate for ultra-short pulses. Proc. SPIE 2017, 10091, 100910J.

32. Neuenschwander, B.; Kramer, T.; Lauer, B.; Jaeggi, B. Burst mode with ps- and fs-pulses: Influence on the removal rate, surface quality and heat accumulation. Proc. SPIE 2015, 9350, 93500U.

33. Neuenschwander, B.; Jaeggi, B.; Zavedeev, E.V.; Arutyunyan, N.R.; Pimenov, S.M. Heat accumulation effects in laser processing of diamond-like nanocomposite films with bursts of femtosecond pulses. J. Appl. Phys. 2019, 126, 115301. [CrossRef]

34. Jaeggi, B.; Neuenschwander, B.; Hunziker, U.; Zuercher, J.; Meier, T.; Zimmermann, M.; Selbmann, K.H.; Hennig, G. Ultra-highprecision surface structuring by synchronizing a galvo scanner with an ultra-short-pulsed laser system in MOPA arrangement. Proc. SPIE 2012, 8243, 82430K.

35. Jaeggi, B.; Neuenschwander, B.; Meier, T.; Zimmermann, M.; Hennig, G. High precision surface structuring with ultra-short laser pulses and synchronized mechanical axes. Phys. Procedia 2013, 41, 319-326. [CrossRef]

36. Landau, L.D.; Lifshitz, E.M. Theory of Elasticity, 3rd ed.; Butterworth-Heinemann: Oxford, UK, 1986 ; Volume 7.

37. Erdemir, A.; Donnet, C. Tribology of diamond-like carbon films: Recent progress and future prospects. J. Phys. D Appl. Phys. 2006, 39, R311-R327. [CrossRef]

38. Merkle, A.P.; Erdemir, A.; Eryilmaz, O.L.; Johnson, J.A.; Marks, L.D. In situ TEM studies of tribo-induced bonding modifications in near-frictionless carbon films. Carbon 2010, 48, 587-591. [CrossRef]

39. Zhao, F.; Li, H.X.; Ji, L.; Mo, Y.F.; Quan, W.L.; Dua, W.; Zhou, H.D.; Chen, J.M. Superlow friction behavior of Si-doped hydrogenated amorphous carbon film in water environment. Surf. Coat. Technol. 2009, 203, 981-985. [CrossRef]

40. Ronkainen, H.; Varjus, S.; Holmberg, K. Friction and wear properties in dry, water- and oil-lubricated DLC against alumina and DLC against steel contacts. Wear 1998, 222, 120-128. [CrossRef]

41. Gachot, C.; Rosenkranz, A.; Hsu, S.M.; Costa, H.L. A critical assessment of surface texturing for friction and wear improvement. Wear 2017, 372-373, 21-41. [CrossRef] 
42. Kovalchenko, A.; Ajayi, O.; Erdemir, A.; Fenske, G. Friction and wear behavior of laser textured surface under lubricated initial point contact. Wear 2011, 271, 1719-1725. [CrossRef]

43. Spikes, H.A. Film-forming additives-Direct and indirect ways to reduce friction. Lubr. Sci. 2002, 14, 147-167. [CrossRef]

44. Hsu, S.M.; Yang, J.; Diann, H.; Huan, Z. Friction reduction using discrete surface textures: Principle and design. J. Phys. D Appl. Phys. 2014, 47, 335307. [CrossRef]

45. Meyer, G.; Amer, N.M. Simultaneous measurement of lateral and normal forces with an optical-beam-deflection atomic force microscope. Appl. Phys. Lett. 1990, 57, 2089-2091. [CrossRef]

46. Ogletree, D.F.; Carpick, R.W.; Salmeron, M. Calibration of frictional forces in atomic force microscopy. Rev. Sci. Instr. 1996, 67, 3298-3306. [CrossRef]

47. Binggeli, M.; Mate, C.M. Influence of capillary condensation of water on nanotribology studied by force microscopy. Appl. Phys. Lett. 1994, 65, 415-417. [CrossRef]

48. Cappella, B.; Dietler, G. Force-distance curves by atomic force microscopy. Surf. Sci. Rep. 1999, 34, 1-104. [CrossRef]

49. Ando, Y.; Ino, J. Friction and pull-off forces on submicron-size asperities. Wear 1998, 216, 115-122. [CrossRef]

50. Stifter, T.; Marti, O.; Bhushan, B. Theoretical investigation of the distance dependence of capillary and van der Waals forces in scanning force microscopy. Phys. Rev. B 2000, 62, 13667-13672. [CrossRef]

51. Cai, S.; Bhushan, B. Meniscus and viscous forces during separation of hydrophilic and hydrophobic surfaces with liquid-mediated contacts. Mater. Sci. Eng. R 2008, 61, 78-106. [CrossRef]

52. Charitidis, C.A.; Koumoulos, E.P.; Dragatogiannis, D.A. Nanotribological behavior of carbon based thin films: Friction and lubricity mechanisms at the nanoscale. Lubricants 2013, 1, 22-47. [CrossRef] 